\title{
НАУЧНЫЙ РЕЗУЛЬТАТ КАК ПРЕДМЕТ ЛОГИКО-МЕТОДОЛОГИЧЕСКОГО АНАЛИЗА
}

Введение. Известны негативные последствия, вызываемые многозначностью, расплывчатостью, неясностью выражений используемого языка: возрастает мера его неопределенности, возникают условия для появления мнимых доказательств, паралогизмов, софизмов, затрудняется взаимопонимание между членами научного сообщества. В сфере правовой и управленческой деятельности подобные явления чреваты экономическими, моральными, психологическими и прочими издержками.

Важнейшим нормативным правовым актом Республики Беларусь (как и других стран постсоветского пространства) в области научных исследований является ныне действующее Положение о присуждении учёных степеней и присвоении учёных званий (дальше - Положение). Его главная функция состоит в формулировке критериев качества диссертаций. Эти критерии призваны играть роль фильтра, пропускающего те и только те из возможных результатов, которые в то же время являются результатами, заслуживающими положительной оценки. Естественно, что корректность формулировок этих критериев - непременное условие их применения. В противном случае нередко приходится иметь дело с требованием «найди то, сам не знаю что».

Возьмём, к примеру, фрагмент Положения, где предъявляются требования к кандидатской и докторской диссертациям: «Кандидатская диссертация должна содержать новые научные теоретические и (или) экспериментальные результаты по одному из актуальных направлений научных исследований. Докторская диссертация должна быть посвящена разработке нового научного направления или концептуальному развитию одного из существующих актуальных научных направлений и содержать принципиально новые результаты, совокупность которых является крупным достижением в соответствующей отрасли науки». Сразу возникает ряд вопросов: «Что такое научный результат, тем более, новый?», «Чем отличается принципиально новый научный результат от просто нового?», «Каким критерием измеряется крупное достижение в соответствующей отрасли науки и чем оно отличается от некрупного?» и др.

В научной литературе, как и в соответствующих нормативных правовых документах, отсутствует удовлетворительное определение понятия научного результата. Поэтому в целом неясным остаётся вопрос о содержании другого важного понятия - понятия научного открытия. В логике такая нежелательная ситуация квалифицируется как «определение неизвестного через неизвестное». Стало быть, понятие научного результата и его важнейший признак «новизна» заслуживают особого анализа. Попытаемся рассмотреть этот вопрос с точки зрения логики и методологии науки.

Научный результат как логико-методологическая проблема. Научные результаты могут принимать разные формы и выступать в виде фактов, теорий, гипотез, проблем, задач и т.д. Они являются предметом изучения ряда наук прежде всего теории познания (гносеологии, Эпистемологии), логики, психологии научного творчества, истории науки. Поэтому по вопросам, связанным с природой научного резуль- 
тата, естественно обратиться именно к этим авторитетным дисциплинам.

В ряде случаев научные результаты, их новизна воспринимаются как нечто само собой разумеющееся. Сюда следует отнести прежде всего случайные открытия. В истории науки таковых было, пожалуй, не меньше, чем запланированных. Многие примеры таких открытий стали хрестоматийными. Таковы открытия планеты Уран Гершелем, первого практически пригодного способа фотографии Дагером, обнаружение особого рода лучей Рентгеном, естественной радиоактивности солей урана Беккерелем и т.д. Автору неизвестны диссертационные исследования, содержащие подобного рода открытия. Видимо, это и понятно, ибо диссертация по своей сути должна отличаться внутренним единством всех своих компонентов - цели и задач, защищаемых положений, используемых методов и полученных выводов. Случайное же находится за рамками области поиска возможных решений, не детерминировано этой областью и её методами, поэтому не предсказуемо в процессе исследования. И.Кант даже не считал случайное открытие достоинством человеческого ума. «Открытие может быть заслугой, - писал он. Но можно найти нечто такое, чего и не искали (как один алхимик нашёл фосфор), но тогда в этом нет никакой заслуги» (Кант 1966: 465-466).

Обычно не вызывает сомнений новизна результатов, полученных с помощью правдоподобных выводов: аналогии, различного рода редуктивных рассуждений (индукции, абдукции и др.), поскольку при этом очевидно, что в заключениях есть нечто такое, чего нет в посылках. Аналогией объясняют открытие Ньютоном закона всемирного тяготения (на основе сходства между падением яблока и притяжением небесных тел) и открытие Гарвеем кровообращения (сходство между клапанами насосов и вен). С применением индукции Кеплером были установлены законы движения планет относительно Солнца. Архимед, заметив уменьшение веса своего тела в воде, обобщил это наблюдение на все тела, погружённые в жидкость. К этому же классу нового относятся результаты, получаемые с помощью интуиции - как мыслительного процесса, приводящего к результату с низкой степенью правдоподобия. В целом же правдоподобные выводы приводят к заключениям, имеющим, как правило, проблематический или гипотетический характер.

Для всех случаев получения заключений на основе правдоподобных рассуждений характерно то, что поиск нового связан с заранее сформулированными задачами (то есть вопросами, характеризующимися достаточностью средств для своего разрешения) или проблемами (когда средств для устранения трудностей недостаточно).

«Головная боль» многих исследователей в сфере логики и методологии науки - вопрос о том, достигаются ли новые знания дедуктивным путём и обладают ли соответствующие рассуждения творческим характером. Известный английский философ и логик Дж. С. Милль давал эвристическим возможностям дедукции (как мысленному переходу от общего к частному) резко отрицательную оценку. По его мнению, «никакое заключение от общего к частному не может как таковое ничего доказать, потому что из общего правила мы можем вывести исключительно те случаи, которые само правило принимает за известные» (Избранные труды русских логиков XIX века 1956: 3).

Позже, в XX веке, его позиция нашла горячую поддержку среди многих сторонников неопозитивистской ориентации.

Принятие идеи о тривиальности и неинформативности дедуктивного процесса неизбежно 
приводит к выводу: поскольку некий субъект знает об $M$ и переход от $M$ к $N$, согласно правилам дедукции, не добавляет ничего нового к тому знанию, которое имеется у субъекта об $M$, то, следовательно, этот субъект знает уже и об $N$, а в таком случае процесс решения не содержит элементов новизны и не носит творческого характера.

Однако в научном сообществе выводы Дж.С.Милля и его последователей натолкнулись на серьезные возражения. Конкретноисторический материал свидетельствовал не в пользу рассуждений, благодаря которым предполагается такой «всеведущий» субъект. «Все мы знаем и верим в большое количество таких вещей, - заметил финский ученый Я. Хинтикка, - о следствиях которых у нас нет ни малейшего представления. Евклид не знал всего, что можно знать в элементарной геометрии, и Максвелл не знал всего, что можно знать об электромагнетизме» (Хинтикка 1980: 230).

Научный результат как предмет диалоги-

ки. Исследования семантики дедуктивных правил и выводов в 30-е годы прошлого столетия привели к результатам, имеющим важное мировоззренческое и методологическое значение. В частности, польский логик А.Тарский доказал теорему о невозможности обсуждения проблемы истинности высказываний данного формализованного (дедуктивно построенного) языка в рамках самого этого языка (Тарский 1999: 14156) Проблема истинности такого рода высказываний, согласно этой теореме, может быть корректно поставлена и решена лишь в рамках метаязыка.

Но поскольку в науке понятие нового обычно сопрягается с понятием истинного (новое знание, в соответствии с природой науки, в конечном счёте должно быть истинным), то вполне правомерны высказывания об ограниченности абстракций и идеализаций, на которых строятся выводы позитивистски настроенных исследователей относительно творческой природы дедуктивных рассуждений. Эти абстракции и идеализации имеют отношение к сфере синтаксиса (как дисциплины, изучающей отношения между знаками и знаковыми системами) и семантики (её предмет - отношения знаков и знаковых систем к обозначающим ими предметам). Однако они чужды прагматике, которая изучает отношения между знаками и знаковыми системами, с одной стороны, и их потребителями, с другой. Прагматика вторгается в сферу социокультурных, ценностных, психологических отношений и является более общим, метаязыковым уровнем анализа по сравнению с синтаксисом и семантикой. Стало быть, тайну нового познавательного результата (и, следовательно, открытия как его частного случая) следует исключить из области той логики, которая традиционно сводит свои задачи к изучению семантико-синтаксических языковых уровней. Постановка вопроса о новизне научного результата в рамках дедуктивной теории оказывается некорректным. Этот вопрос правомерно перенести на более общий, прагматический уровень, в частности, в сферу диалогики -раздела прагматики, где исследуются проблемы общения между людьми, прежде всего проблемы вербального диалога.

Диалогизм - сущностная черта человеческого бытия. Ф.Достоевским убедительно показано, что в диалоге «человек не только проявляет себя вовне, а впервые становится тем, что он есть, ... не только для других, но и для самого себя. Быть - значит общаться диалогически.

Когда диалог кончается - всё кончается. Поэтому диалог в сущности не может и не должен кончиться» (Философия и логика ЛьвовскоВаршавской школы 1999: 153). Примечательно, что даже тогда, когда человек задумывается о 
чём-то, оставаясь наедине с самим собой, он задаёт себе вопросы и сам ищет на них ответы, сам выдвигает идеи и сам их критикует, то есть он мыслит в форме диалога (такой диалог называется внутренним). Философ В.Библер описывает ситуацию следующим образом: ""Я" утверждаю нечто. "Я" отвергаю это нечто и выдвигаю другое предположение. "Я" - в ответ - усиливаю свои исходные аргументы, но тут же "g" развиваю свое ответное предположение... Короче, я мыслю» (Бахтин 1994: 55).

Новые мысли рождаются в головах одиночек, но, по образному выражению одного автора, «одинокая мысль бесплодна, как папский дискант» (Библер 1990: 267). Полученная способом внутреннего диалога, истина требует выхода во внешнее пространство, представления на суд научного сообщества. «После того, как истина найдена, - писал акад. Б.М.Кедров, - задача, стоящая перед исследователем, сразу и резко меняется - от её поисков любыми путями и средствами он немедленно переходит к тому, чтобы оптимальным путём довести её до учёного мира, а главное - убедить этот мир в её действительной ценности» (Глазман 1969: 55). Публикация - важнейшая форма оповещения учёного мира о появлении нового продукта. Она даёт толчок внешнему диалогу, фактически с публикации начинается этап социализации этого продукта, то есть этап его общественного признания. Только учёному миру судить, является ли этот продукт истинным и новым результатом.

Можно выделить три уровня, три этапа существования и социализации новой истины - истина «в себе», истина «лично для меня» и истина «для некоторых» (в смысле «для некоторых, а может быть, для всех», как это принято в аристотелевской логике). Истина «в себе» - ещё не обнаруженные связи объективной действительности. Она существует безотносительно к субъ- ективному мышлению, восприятию, переживанию, к любому индивидуальному акту сознания. Это, так сказать, нулевой уровень социализации. Истина «лично для меня» немыслима без учета субъективного, индивидуального аспекта ее становления. Внутренний диалог - естественный способ его оформления и бытия. Не может быть истины «лично для меня», если истине «в себе» нет доверия со стороны «лично меня», познающего индивидуального субъекта, то есть если она для него не достоверна. Таким образом, истина «лично для меня» есть удостоверенная истина «в себе» в рамках некоторой индивидуальной концептуальной системы. Она может стать истиной «для некоторых» в процессе её испытания и, в конечном счёте, признания представителями определённой социальной (в частности научной) общности, элементом которой «я» является.

Необходимым условием превращения истины «в себе» в истину «лично для меня» и, далее, в истину "для некоторых» является возможность подведения истины «в себе» под имеющуюся у субъекта познания совокупность категориальных структур - предпосылок мировоззренческого, аксиоло-гического, методологического, научно-теоретического, психологического и прочего характера (Кедров 1971: 70-77). Процесс этого превращения связан с внешним диалогом, в котором исключительная роль принадлежит особой логико-коммуникативной процедуре - аргументации. Задача аргументации состоит в том, чтобы владелец категориальных структур воспринял, понял и, наконец, принял истину «в себе», «открыл» её для себя, сделал её своей собственной.

Деятельностная природа научного результата. Приведенные соображения могут навести на мысль о том, что ключ к решению проблемы научного результата и, далее, к раскрытию сути 
феномена открытия находится исключительно в сфере субъект-субъектных отношений, в сфере вербальной коммуникации, диалога. Но тогда придётся согласиться с Платоном, который утверждал, что познание есть особого рода припоминание, которое лишь возвращается к уже известному и потому, в соответствии с современными интерпретациями, не может давать ничего нового о внешнем мир.

Коллизия снимается с учётом того обстоятельства, что у процесса познания есть другая, не менее важная, субъект-объектная сторона, что познание есть единство коммуникации и деятельности - процесса, направленного на отображение свойств объективной реальности. При этом, как показано в исследованиях А.Брушлинского и В.Поликарпова, по ходу познания субъект-объектные отношения доминируют над субъект-субъектными, являются фундаментальными по отношению к ним. Лишь проникнув в объект, раскрыв его, субъект (личность, социальная группа, человеческое общество) обращает полученные результаты в предмет специальной рефлексии и коммуникации в целях доказательства истинности, существенности, новизны и общественной значимости полученного результата (Берков 2007: 63). Таким образом, в науке результат признаётся за истинный и новый в процессе общения, диалога (первоначально внутреннего, затем внешнего), то есть в сфере субъект-субъектных отношений. Однако порождается и добывается он благодаря исследовательскому труду, в сфере субъект-объектных отношений.

Обобщённая схема исследовательского процесса. Так как всякая исследовательская деятельность имеет сходные черты, то существует возможность представить её в виде обобщённой схемы. Поэтапно она выглядит следующим образом: а) формулировка цели исследования;

б) постановка подчиненных ей задач (подцелей);

в) выдвижение гипотез;

г) выбор методов исследования;

д) обоснование гипотез;

е) выводы.

Как правило, эта схема конкретизируется в зависимости от предмета исследования.

Пункты а), б), в) и е) являются узловыми в данной схеме - в том смысле, что здесь фиксируются достаточно оформленные положительные результаты познавательного процесса: проблема, гипотеза, аподиктический, то есть безусловно достоверный, основанный на необходимости, результат (греч. apodeiktikos - достоверный, убедительный). Традиционно отношение научной общественности к проблемам и гипотезам является, как правило, более умеренным, прохладным, чем к аподиктическим результатам (научным законам, теориям, фактам и пр.). За постановку проблем, выдвижение гипотез не присуждают учёных степеней, тем более Нобелевских премий. Вместе с тем, проблемы и гипотезы - необходимые формы воплощения исследовательского процесса, складывающиеся и существующие на промежуточных этапах его развития, в то время как аподиктический результат - его конечный пункт.

Исключительное влияние «научной проблемы» (как категории) на судьбы научного исследования отмечено в науковедении уже давно. Обратим внимание на утверждения одного из крупнейших математиков XX столетия Д.Гильберта. «Каждый век имеет свои проблемы, которые последующая эпоха или решает, или отодвигает в сторону, как бесплодные, чтобы заменить их новыми, - заявил он на II Всемирном конгрессе математиков (1900 г.). - Чтобы представить возможный характер развития матема- 
тического знания в ближайшем будущем, мы должны перебрать в нашем воображении вопросы, которые остаются нерешенными, обозреть проблемы, которые ставит современная наука и решения которых мы ждем от будущего... Всякая научная область жизнеспособна, пока в ней имеется избыток новых проблем; отсутствие проблем предвещает отмирание или прекращение самостоятельного развития... В решении проблем исследователь укрепляет свои силы, находит новые методы и новые точки зрения, открывает более широкие и свободные горизонты» (Брушлинский 1988: 100-101).

Способность к правильной постановке проблем считается важнейшим показателем научности стиля мышления. Преклонение перед готовыми ответами ведет к догматизму, конформизму, бессмысленному начетничеству, к умерщвлению науки. Некоторые исследователи склонны полагать, что в науке проблемы превалируют над достоверным знанием и составляют ее основную ценность. Рассматривая роль философских проблем, В. Гейзенберг, например, писал, что ответы «в большинстве случаев носят преходящий характер, они теряют в ходе времени свое значение благодаря расширению наших знаний о фактах» (Гейзенбер 1958: 61). Проблемы же непреходящи, и наука вынуждена периодически возвращаться к их рассмотрению. «Можно снова поставить очень старые философские вопросы, занимавшие человеческий разум со времени самых ранних эпох философии и науки: конечно или бесконечно пространство? Что было до начала времени? Или у времени нет ни начала, ни конца», - не без оснований полагал В.Гейзенберг (Гейзенберг 1963: 97).

Особый класс - мнимые проблемы науки. Их общим и существенным признаком является внутренняя противоречивость. Мнимые проблемы неразрешимы, то есть они характеризуются принципиальной невозможностью получения положительного результата. Но, как говорят, отсутствие результата есть тоже результат. Ценность отрицательного результата состоит в том, что он, закрывая собой один из ложных путей научного поиска, тем самым сужает его поле или наводит на мысль о переформулировке проблемы. Классическими примерами мнимых проблем могут служить поставленные ещё в древности задачи на построение с помощью циркуля и линейки квадрата, равновеликого данному кругу («квадратура круга»), на удвоение куба, трисекцию угла. Доказательство невозможности положительного решения этих задач было одним из величайших достижений математической мысли. Средства для такого доказательства появились через три тысячелетия после их постановки, на том этапе развития математики, когда были открыты трансцендентные числа и начала разрабатываться их научная теория (конец XIX в.).

Процесс разрешения действительной проблемы приводят к рождению гипотез. Их роль в науке чрезвычайно велика. Об том писал Ф.Энгельс: «Формой развития естествознания, поскольку оно мыслит, является гипотеза. Наблюдение открывает какой-либо новый факт, делающий невозможным прежний способ объяснения фактов, относящих к той же самой группе. С этого момента возникает потребность в новых способах объяснения, опирающегося сперва не только на ограниченное число фактов и наблюдений. Дальнейший опытный материал приводит к очищению этих гипотез, устраняет одни из них, исправляет другие, пока, наконец, не будет установлен в чистом виде закон» (Кант 1964: 191).

Вряд ли можно отдать предпочтение аподиктическим конструкциям перед проблематическими или гипотетическими, если рассматри- 
вать их место и роль в структуре исследовательского процесса. Каждая из этих конструкций обладает своей познавательной ценностью, является положительным научным результатом, то есть научным достижением. Но в отличие от аподиктических суждений, с помощью которых фиксируются научные факты, законы и их системы (теории), проблематические и гипотетические не обладают свойством истинности и, в силу этого, не столь значимы в практическом отношении. Важно иметь в виду и то, что эти конструкции погружены в контекст деятельности и общения и потому окрашены в субъективные человеческие тона). Например, возникновение некоторого противоречия в науке - объективный процесс, но соответствующая этому противоречию проблема складывается лишь с появлением субъективной потребности в его устранении.

Тернистые пути открытия. В «Словаре русского языка» С.жегова открытие определяется как новая истина. Достоинство этой дефиниции не только в её простоте. Важно, что она даётся в терминах прагматики и ею «схвачены» как субъект-субъектная, так и субъект-объектная характеристики определяемого предмета - открытия. Этой дефиницией за грань рассмотрения выводятся те виды научных достижений, которые фиксируются с помощью проблематических и гипотетических языковых средств.

Вместе с тем, данная дефиниция не достаточна, она является слишком широкой. Ей охватывается как «истина для некоторых», так и «истина лично для меня». Однако последняя - не обязательно открытие. Она может им и не быть вообще, если, например, “для некоторых» она уже известна (ситуация «изобретения велосипеда») или в процессе исследования получены данные, которые являются избыточными, «шумовыми» по отношению к предполагаемому ре- зультату. Поэтому требуются определённые уточнения.

В процессе познания отношение субъекта к познаваемому объекту и к другим субъектам (вернее, к их мыслям) носит избирательный характер. «Субъект видит только то, - писал И.Кант, - что сам создаёт по собственному плану, ... он с принципами своих суждений должен идти вперёд согласно постоянным законам и заставлять природу отвечать на его вопросы, а не тащиться у неё словно на поводу» (Ливанова 1969: 85). Поэтому для субъекта нечто не отличается новизной и, тем более, не становится открытием, если это нечто не совместимо с кругом его (субъекта) понятий и убеждений. Такое нечто воспринимается скорее как нонсенс, псевдооткрытие, поскольку не отвечает надеждам, запросам и интересам этого субъекта. Классическим примером может служить отношение современников к геометрии Лобачевского на первом этапе её существования - от провозглашения до признания (1826-1868 гг.).

Н.Лобачевский впервые сообщил о созданной им геометрии в докладе на заседании Совета Казанского университета 11 февраля 1826 года. Однако он потерпел фиаско в глазах присутствующих. Как пишет историограф А.Ливанова, «современники Лобачевского, кому судьба подарила счастье услышать изложение основ новой великой науки из уст его первооткрывателя, - даже эти люди не только ничего не поняли, они не сделали попытки что-либо понять. Слова о необычайном и сложном, почти фантастическом строении мира, эти слова, сказанные впервые на земле, были обращены к глухим. Да, к глухим, потому что и слабого волнения ума не вызвали они у слушателей. Мысль их спала непробудным сном» (Кузнецова 1987: 38). Комиссия из членов Совета, которая должна была дать заключение о сообщении Лобачевского, оказа- 
лась несостоятельной. Никто не проявил интереса к дальнейшему обсуждению содержащихся в докладе идей, и, таким образом, полученная Лобачевским истина «истиной для некоторых» не стала. В научном сообществе не возник вопрос даже о новизне представленного результата, не говоря уже о его истинности.

В других случаях новизна результата не ставится под сомнение, но учёные оказываются как бы под гипнозом предвзятых представлений и потому противятся признанию его ценности. Профессор Седжвик, учитель Ч.Дарвина, отказался принять от последнего в подарок его знаменитую книгу, заявив, что он оскорблён содержащимися в ней идеями. Кандидатуру великого англичанина дважды выдвигали в почётные члены французской академии, и оба раза учёные мужи проваливали её. В Германии была выбита свинцовая печать, на которой Дарвин изображался в карикатурном виде. Креационисты до сих пор упорно отвергают как ложную, якобы построенную на пустом месте эволюционную теорию Дарвина и её продолжение - синтетическую теорию эволюции.

Курьёзно выглядят случаи, когда по причине несовместимости старых представлений с полученными результатами учёные отказывали в эвристических достоинствах даже собственным изысканиям. Выдающийся физик М.Планк, с именем которого связывается рождение квантовой теории, не считал своей особой заслугой введение кванта действия (постоянная Планка) и лишь через десять с лишним лет прекратил попытки примирения идеи квантовых порций энергии с непрерывностью как важнейшим понятием классической физики. Новый истинный результат не принимал статуса открытия даже в глазах самого учёного. Как пишет Н.Кузнецова, «не Планк был революционером по своим установкам и целям, а скорее физикаXX века сделала его революционером в своей рефлексии» (Дуэль 1985: 217).

Что же касается чужих трудов, то предвзятое к ним отношение - обычное дело. Но в конечном счёте "истина торжествует" (veritas vincit, по выражению древних римлян) или при определённых обстоятельствах противники вынуждены по крайней мере с ней считаться. Что же это за обстоятельства? Рассмотрим этот вопрос на примере одной из «вечных» научных проблем - происхождение материков и океанов.

В начале 50-х годов XIX в. из работ французского исследователя Э. де Бомона родилась так называемая концепция контракции (в переводе с латыни - сжатия). Суть её такова. Земля, представлявшая в момент своего рождения огненно-жидкое тело, со временем, остывая, покрылась твёрдой корой. Ядро же Земли и лежащая над ним оболочка до сих пор раскалены. Они продолжают остывать, отдавая сквозь кору своё тепло в мировое пространство, а значит, и сжимаются, уменьшаются в объёме. При этом должна уменьшаться и земная кора. Но поскольку она твёрдая, не пластичная, то сжиматься может морщась, образуя складки. Примерно так сжимается и морщится кожура усыхающего яблока. Однако земная кора на сокращение объёма глубинных слоёв реагирует болезненнее, чем яблочная кожура, она не только морщится, но ещё и разрывается. Через гигантские трещины вырывается на поверхность раскалённая магма. Одни участки коры от движения вещества в глубинах воздымаются, другие - проседают, что, в свою очередь, приводит к созданию в подкорковых слоях очагов напряжения, которые, разряжаясь, вызывают землетрясения, оползни, извержения вулканов.

Эта концепция быстро заняла почётное место в мире науки, но не беспричинно. Во-пер- 
вых, практически все факты, известные наукам о Земле к тому времени, получали с её помощью убедительное для современников объяснение. Во-вторых, развитие геологической науки в последующие десятилетия не давало повода для сомнений: новые факты также легко встраивались в эту гипотезу, подтверждая её. В-третьих, её поддержали, а затем усиленно пропагандировали авторитетнейшие геологи и геофизики того времени, отчего любой скепсис по её поводу казался неуместным; в-четвертых, гипотеза была просто, доступно и даже изящно преподнесена, в связи с чем крупный специалист в области геофизики О.Сорохтин заметил: «Гипотеза контракции была исключительно красивой концепцией, и именно её красота и кажущаяся физичность гипнотизировала учёных почти 100 лет (до 30-х годов нашего века)» (Гоббс 1991: 35).

Короче, концепция контракции, вобрав в себя все достижения науки прошлого, была всесторонне и тщательно аргументирована, и это было тем «определённым обстоятельством», которое сделало её приемлемой в сообществе геологов, геофизиков и других представителей наук о Земле. Более того, в глазах учёных она приобрела даже статус научной теории, и в этой роли вошла в вузовские и школьные учебники. На самом же деле, это было псевдооткрытие.

В период господства концепции контракции раздавались и другие голоса. В частности, высказывались мнение о том, что причиной образования материков и океанских впадин являются горизонтальные перемещения глыб земной коры. Но голоса представителей этой точки зрения были очень слабыми и робкими, к тому же указанные перемещения объяснялись ими, как правило, совершенно фантастическими и нереальными процессами.
И вот в 1915 году выходит книга немецкого учёного А.Вегенера «Возникновение материков и океанов». В ней не только высказывается, но и обосновывается идея дрейфа материков при тончайшем анализе огромного количества сведений из разных наук - геофизики, геологии, палеонтологии, биологии, палеоклиматологии. Даже яростным противникам этой идеи не просто было отмахнуться от приведенных доводов. Она сразу же нашла себе множество почитателей, получила дальнейшее развитие в трудах учёных многих стран. Она не имеет убедительных контр доводов по сегодняшний день и приобрела, таким образом, аподиктический характер.

Судьба концепций возникновения материков и океанских впадин является свидетельством того, что «для некоторых» научные результаты могут как «открываться», так и «закрываться», - в соответствии с тем, являются они положительными или отрицательными с точек зрения этих «некоторых». В ряде случаев вопрос решается пристрастно, в соответствии не только с социокультурными и ценностными, но даже конъюнктурными и сиюминутными установками субъектов, и то, что в одном из субъективных «возможных миров» является положительным результатом, в другом - отрицательным, и наоборот (по Маяковскому, подходят к «верблюду» с «лошадиными мерками» или наоборот). В связи с этим нельзя не вспомнить язвительное замечание английского философа Т.Гоббса: «Если бы истина, что три угла треугольника равны двум углам квадрата, противоречила чьему-либо праву на власть или интересам тех, кто уже обладают властью, то, поскольку это было бы во власти тех, чьи интересы задеты этой истиной, учение геометрии было бы если не оспариваемо, то вытеснено сожжением всех книг по геометрии» (Берков 2012: 79). 
По нашему мнению, подлинный научный интерес адекватен совокупности двух основных целей: во-первых, новый результат должен быть объективно истинным (то есть отображающим явления и закономерности действительности в рамках исторически сложившихся познавательных форм такими, какими они существуют вне и независимо от воли, мнений, пристрастий и прихоти исследователя); во-вторых, он должен быть логически обоснованным (то есть непротиворечиво включенным в систему ранее добытых знаний и гуманистических ценностей). Наряду с объективной истинностью и логической обоснованностью научному результату должны быть присущи и другие особые характеристики системность, эссенциальность (лат essentia сущность), практическая полезность, общезначимость, специфический для данной научной области язык. Однако последние признаки являются производными от основных - объективной истинности и логической обоснованности (Левин 2004: 84-86).

В диалоге, разворачивающемся по поводу чьей-то «истины для меня», как основные, так и производные признаки выступают в качестве средств, критериев, с помощью которых формируется или отвергается новая «истина для некоторых». Как открытие «воображаемая геометрия» Лобачевского не существовала в науке до тех пор, пока не была доказана её практическая полезность при описании свойств поверхностей отрицательной кривизны. По причине сомнительной полезности в настоящее время вряд ли заслужит особого внимания учёного мира уточнение очередного знака после запятой в числе $\pi$ (за будущее ручаться не будем).

Авторитет концепции контракции в геологии был окончательно подорван обнаружением радиоактивного распада элементов, сопровождающего выделением тепла, и, тем самым, оп- ровержением важнейшей опоры этой концепции - утверждения о том, что Земля есть остывающее тело («усыхающее яблоко»). Концепция контракции не вписывалась больше в систему развивающихся знаний и в настоящее время представляет лишь исторический интерес.

Английский астроном Дж. Адамс поставил заслон своему собственному открытию - теоретическому обоснованию размеров и координат доселе неизвестной планеты (впоследствии она была названа Нептуном) - тем, что не представил на суд астрономического научного мира должных объяснений. Аналогичные результаты позже (но не намного) получил француз У.Леверье, которому и досталась «пальма первенства», поскольку с точки зрения доказательности его работа не вызвала претензий.

Однако отмечая значение критериев обоснования, не следует забывать, что их абсолютизация (даже отдельных из них) чревата, как правило, негативными последствиями. Фактически дело заканчивается псевдооткрытиями, как это случилось с экспериментами Т.Лысенко, «обещающими» решение актуальной практической задачи - достижения продовольственного изобилия в СССР, с работами по синтезу вредоносного дДт (дуста), которые были удостоены Нобелевской премии, с многими технократическими проектами. Во всех этих случаях самодовлеющая роль придавалась критерию практической полезности. Г.Левин, в целом положительно оценивая значение этого критерия, вместе с тем пишет: «История применения этого критерия в нашей стране - это история наших бедствий. Резолюция "Не имеет народно-хозяйственного значения" является эпитафией на "могилах" многих выдающихся отечественных открытий. Однако вред, который использование невеждами критерия практической полезности нанесло 
отечественной науке, не доказывает вреда самого критерия» (Якушев 2008: 46).

Завершая этот раздел, добавим следующее. С именами Коперника, Лобачевского, Дарвина, Эйнштейна и многих других великих учёных связаны открытия, которые произвели революцию В воззрениях не только на окружающий мир, но и на самого человека. Но эти открытия стали возможны благодаря другим достижениям, не столь эпохальным. Уместно вспомнить слова великого ученого XX в. Н.Винера, который в своей книге «Я - математик» писал, что 95 \% оригинальных научных работ принадлежит менее чем $5 \%$ профессиональных ученых, но большая часть из этих работ вообще не появилось бы, если бы остальные 95 \% не содействовали созданию общего достаточно высокого уровня науки. И вопрос не в том, точно ли определены Н.Винером названные соотношения. Важно, что им отмечена ценность повседневной работы рядовых тружеников, рождающей даже не всегда заметные достижения - миниоткрытия, которые обеспечивают эволюционное развитие науки и создают фундамент для революционных сдвигов в общественном сознании. Крупные, средние и мелкие открытия - размытые понятия, связанные между собой едва ли уловимыми переходами.

Диссертация как диалог и как открытие. Теперь вернёмся к вопросам, поставленным во вводной части данной статьи. Сопоставим два ключевых утверждения Положения: 1) «Кандидатская диссертация должна содержать новые научные... результаты» и 2) «Докторская диссертация должна... содержать принципиально новые результаты». Очевидно, что требуется уточнение понятия принципиально нового результата, однако законодатель этого не делает. Отсюда трудности при рассмотрении диссертационных работ, поскольку эксперт вынужден руко- водствоваться интуитивными, а не объективными критериями новизны и существенности полученных в них результатов. Такую ситуацию нельзя считать нормальной. К этому выводу приходят многие исследователи. Предлагаем, скорее, в порядке обсуждения, следующий подход.

То, что деятельность и общение (соответственно, субъект-объектные и субъект-субъектные отношения) - две взаимосвязанные стороны единого познавательного процесса, является общепринятым в марксистской философской литературе. Многие экономисты, социологи, психологи, праксеологи и др. принимают и успешно конкретизируют этот тезис. Однако по неясной причине в качестве методологического регулятива он слабо проявляет себя в сфере управления научными процессами, в частности при планировании, организации, регулировании, контролировании и оценке диссертационных исследований.

Изложенное выше наводит на мысль о допустимости рассмотрения диссертаций через призму теории диалога. Эта теория имеет логический аспект, наиболее удачно отображённый и зафиксированный в так называемой интеррогативной (лат. interrogativus - вопросительный) логике, или в логике вопросов и ответов. Представляется, что «погружение» диссертационных работ в контекст понятийно-терминологического аппарата интеррогративной логики создаёт основу для их более чёткой классификации.

С точки зрения интеррогативной логики тема диссертации, а также её цель, подчинённые ей задачи, названия отдельных глав, параграфов, подпараграфов и т.д. интерпретируются как требующие разрешения вопросы. Положения, выносимые на защиту, истолковываются как предположительные, а выводы - как прямые и достоверные ответы на эти вопросы. И если в 
вопросе содержится максимум энтропии (то есть меры неопределенности) информации, то в ответе, выводе должно быть минимум этой меры.

По способу запроса неизвестного выделяются два основных типа вопросов. Для вопросов первого типа (часто их называют вопросами к решению) характерно то, что ответ или его отрицание является элементом структуры вопроса и находится под вопросительным знаком. Постановка таких вопросов сама по себе исчерпывает все возможности, среди которых следует искать ответ. Например, постановка вопроса "Существовала ли Атлантида?" предполагает две возможности ответов - либо "да", либо "нет" (вопросы подобного рода называются дихотомическими). В других случаях таких возможностей может быть больше, как, например, при постановке вопроса "Канада является колонией, доминионом или независимым государством?"

В вопросах второго типа (вопросах к дополнению) намечена лишь схема ответа. В них возможные ответы не содержатся под вопросительным знаком, и часто неясно, сколько их может быть вообще. Например: "Кто убил Джона Кеннеди?", "Каковы причины раковых заболеваний?". Схемой первого вопроса является выражение "х убил Джона Кеннеди", второго - "x, у, Z... суть причины раковых заболеваний". Схема вопроса превращается в ответ при нахождении и подстановке вместо переменных имен (простых или сложных), обозначающих предметы в соответствующей предметной области. В разговорном языке она выделяется вопросительными словами или частицами.

Рискнём предположить, что кандидатская диссертация - сложный, разветвлённый вопрос первого типа, в то время как докторская - не менее сложный и не менее разветвлённый вопрос второго типа. С этой позиции соискатель учёной степени кандидата наук работает в замкнутом пространстве альтернатив, каждая из которых в процессе диалога испытывается и подвергается научной критике по крайней мере по следующим позициям:

- Правомерна ли постановка такого-то вопроса (формулировка темы, задачи, проблемы)?

- Соответствуют ли используемые методы предмету исследования?

- Соответствуют ли используемая терминология логико-методологическим стандартам, а если не соответствует, то как её можно изменить, уточнить, прояснить и т.д.?

- Верны ли аргументы, приводимые для обоснования важнейших положений, а если не верны, то почему?

- Все ли из этих аргументов необходимы?

- Достаточны ли они для принятия такого-то положения?

- Какие из выдвигаемых им положений допустимы лишь в качестве гипотез?

- Правильно ли проведена классификация?

- Нет ли изъянов в структуре изложения данного материала или отдельных его частей?

- Законно ли некоторое рассуждение (дока зательство, опровержение, подтверждение, возражение, объяснение, интерпретация, оправдание и т.д.)?

- Раскрыта ли специфика исследуемого предмета?

- Репрезентативен ли используемый эмпирический материал?

- Какие новые вопросы порождаются соответствующими фактами или теоретическими положениями?

Соискателю докторской степени не достаточно оставаться в рамках замкнутого пространства альтернатив, следовательно, не достаточно рассмотрения такого рода вопросов. Он должен выходить за эти рамки, направляя свою 
деятельность «по рельсам», обозначенным некоторым вопросом второго типа. При этом неизвестное устраняется на пути отыскания (открытия) и подстановки вместо переменной x (y, z, ...) постоянной из определённой, возможно, бесконечной предметной области.

Однако переходя от неизвестного к известному, совершая открытие, нельзя надеяться на успех, игнорируя весь арсенал средств эмпирического, теоретического и философского уровней познания. Узкая специализация и, как следствие, вынужденная ориентация на эмпирические средства исследования, являющаяся одной из тенденций в современной, особенно общественной, науке, могут губительно сказаться на судьбах научных открытий.

Заключение. Научный результат есть ответ на поставленный наукой вопрос (задачу, проблему). Решение об истинности и новизне научного результата принимается в сфере субъектсубъектных отношений, в процессе диалога (внутреннего и/или внешнего), в метаязыке, на прагматическом уровне. Однако порождается и добывается он благодаря исследовательскому труду, в сфере субъект-объектных отношений.

Как этап исследовательского процесса научный результат может носить аподиктический, гипотетический или проблематический харак-

\section{ЦИТИРОВАННАЯ И УПОМЯНУТАЯ ЛИТЕРАТУРА}

1. Кант, И. (1966). Соч. в 6 т. Т. 6. М., изд-во: Мысль.

2. (1956). Избранные труды русских логиков XIX века. М., изд-во: АН СССР

3. Хинтикка, Я. (1980). Логико-эпистемологические исследования. М., изд-во: Наука.

4. Тарский, А. (1999).Понятие истины в языках дедуктивных наук . тер. Аподиктический результат имеет наибольшую ценность в практическом отношении.

Научный результат может стать открытием, при условиях: а) его (результата) аподиктической истинности, б) новизны, в) достаточной аргументированности, позволяющей принимать или не принимать его в данной интеллектуальной среде. Принятие (непринятие) открытия зависит от особенностей господствующих в научном сообществе категориальных структур - предпосылок мировоззренческого, аксиологического, методологического, идеологического, психологического и прочего характера. При этом не исключается появление псевдооткрытий, которые разоблачают себя и устраняются из науки в процессе её дальнейшего развития.

Под деление диссертаций на кандидатские и докторские может быть подведена более твёрдая, по сравнению с существующей, логическая основа. Этой основой может служить способ запроса неизвестного, который направляет исследовательский процесс. Тогда кандидатскую диссертацию можно интерпретировать как разработку некоторого вопроса к решению, а докторскую - к дополнению. В последнем случае неизбежен выход за пределы уже известного, дополнение его новым содержанием.

5. Философия и логика ЛьвовскоВаршавской школы (1999). М., изд-во: Российская политическая энциклопедия (РОССПЭН).

6. Бахтин, М. (1994). Проблемы творчества Достоевского. Москва.

7. Библер, В. (1990). От наукоучения - к логике культуры: два филос. введения в двадцать первый век . Москва.

8. Глазман, И. (1969). Коллектив и научное творчество. М., изд-во : Наука. 
9. Кедров, Б. (1971). Научное открытие и информация о нём. Научное открытие и его восприятие. М., изд-во: Наука.

10. Берков, В. (2007). Этапы и формы социализации научных инноваций Социология, № 2.

11. Брушлинский, А. (1988). Диалог в процессе познания. Познание и общение. М., изд-во: Наука.

12. Гейзенберг, В. (1958). Открытие Планка и основные философские вопросы учения об атомах. Вопросы философии, № 11.

13. Гейзенберг, В.( 1963). Физика и философия. Часть и целое. М., изд-во: Наука.

14. Кант, И. (1964). Соч. в 6 т. М., изд-во: Мысль.

15. Ливанова, А. (1969). Три судьбы. Постижение мира, М., изд-во: Знание.

16. Кузнецова, Н. (1987). Научная рефлексия как объект историко-научного исследова- ния Проблемы рефлексии. Современные комплексные исследования. Новосибирск, изд-во: Наука.

17. Дуэль, И. (1985). Судьба фантастической гипотезы. М., изд-во: Знание.

18. Гоббс, Т. (1991) Соч. в 2 т. М., изд-во: Мысль.

19. Берков, В. (2012). Методология науки. Общие вопросы. Минск, изд-во: РИВШ.

20. Левин, Г. (2004). Принципы теоретической критики. Философские науки, № 3.

21. Якушев, А. (2008). Правовые проблемы оценки результатов диссертаций в России. Материалы международной научнопрактической конференции «Инновации и подготовка научных кадров высшей квалификации в Республике Беларусь и за рубежом» (под ред. И.Войтова). Минск., изд-во: ГУ БелИСА.

БЕРКОВ ВЛАДИМИР

\section{НАУЧНЫЙ РЕЗУЛЬТАТ КАК ПРЕДМЕТ ЛОГИКО-МЕТОДОЛОГИЧЕСКОГО АНАЛИЗА}

\section{PEЗЮME}

В статье в логико-методологическом плане анализируется понятие научного результата, даётся его определение, выделяются его типы. Показывается, как порождаясь и добываясь в процессе исследовательского труда (субъектобъектных отношений), научный результат получает свои важнейшие характеристики - истинности и новизны, в метаязыке, процессе диалога (субъект-субъектных отношений). Выявляются условия становления научного результата как открытия. Предлагается описание диссертационных исследований средствами интеррогативной логики.

Ключевые понятия: научный результат, истинность, новизна, диалог, открытие, диссертация, интеррогативная логика. 


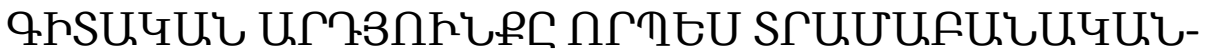

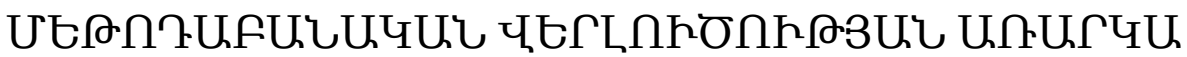

\section{UUФПФПЋU}

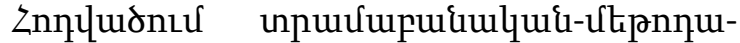

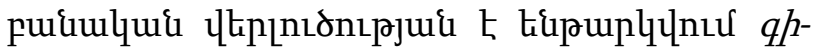

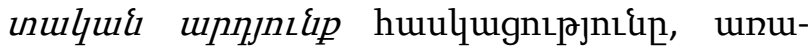

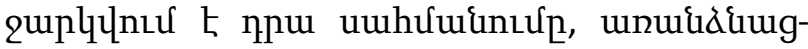

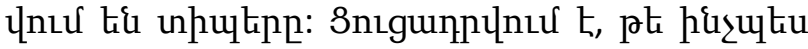

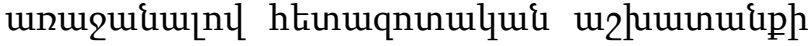

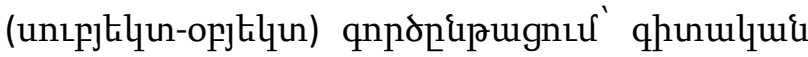

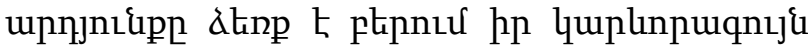

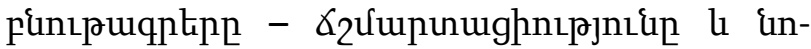

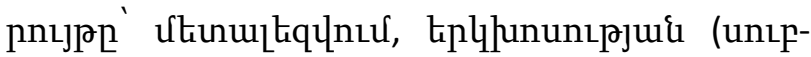

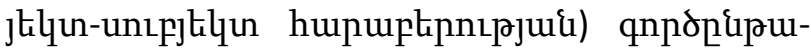

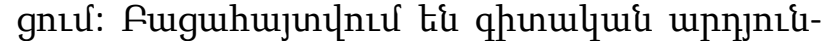
ph npuitu qhunulqui hujuquuqnponıрјuí qu-

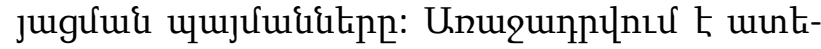

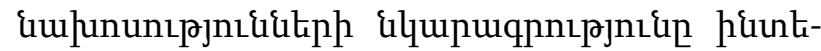
nnquinhl unpurưupuinıpjuid uhengutinnц:

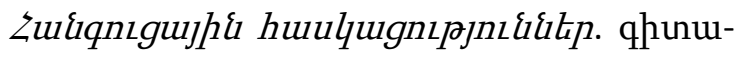

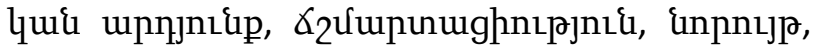
Łplhununıpjnı\{, hujunquaqnponıpjnı\&, uunt-

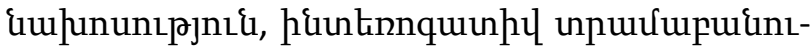
pjnı\&:

BERKOV VLADIMIR

\section{SCIENTIFIC OUTCOME AS A RESULT OF LOGICAL-METHODOLOGICAL ANALYSIS}

\section{SUMMARY}

The paper recaps the analysis of the concept of scientific outcome from logical-methodological standpoint with particular reference to the pertinent nomenclature of its definition and typology. The research establishes the major characteristics attributed to the scientific outcome materialized and gained in the course of research work (within the framework of subject -object relationship), namely: the authenticity and relevance in terms of the academic metalanguage and within the dialogue process (subject - subject relationship). The article reveals the conditions and pre-settings necessary for any scientific outcome to emerge as a discovery. The author sets forth the idea of submitting scientific dissertations (research papers) to evaluative description via interrogative logic.

Key concepts: scientific outcome, authenticity, relevance, dialogue, discovery, dissertation, interrogative logic. 